\title{
Perspective \\ Perspectives on Complexity, Chaos and Thermodynamics in Environmental Pathology
}

\author{
Maurizio Manera (iD
}

check for updates

Citation: Manera, M. Perspectives on Complexity, Chaos and

Thermodynamics in Environmental Pathology. Int. J. Environ. Res. Public Health 2021, 18, 5766. https:// doi.org/10.3390/ijerph18115766

Academic Editor: Patricia Switten Nielsen

Received: 22 April 2021

Accepted: 25 May 2021

Published: 27 May 2021

Publisher's Note: MDPI stays neutral with regard to jurisdictional claims in published maps and institutional affiliations.

Copyright: (C) 2021 by the author. Licensee MDPI, Basel, Switzerland. This article is an open access article distributed under the terms and conditions of the Creative Commons Attribution (CC BY) license (https:// creativecommons.org/licenses/by/ $4.0 /)$
Faculty of Biosciences, Food and Environmental Technologies, University of Teramo, St. R. Balzarini 1, 64100 Teramo, Italy; mmanera@unite.it; Tel.: +39-0861-266980

\begin{abstract}
Though complexity science and chaos theory have become a common scientific divulgation theme, medical disciplines, and pathology in particular, still rely on a deterministic, reductionistic approach and still hesitate to fully appreciate the intrinsic complexity of living beings. Herein, complexity, chaos and thermodynamics are introduced with specific regard to biomedical sciences, then their interconnections and implications in environmental pathology are discussed, with particular regard to a morphopathological, image analysis-based approach to biological interfaces. Biomedical disciplines traditionally approach living organisms by dissecting them ideally down to the molecular level in order to gain information about possible molecule to molecule interactions, to derive their macroscopic behaviour. Given the complex and chaotic behaviour of living systems, this approach is extremely limited in terms of obtainable information and may lead to misinterpretation. Environmental pathology, as a multidisciplinary discipline, should grant privilege to an integrated, possibly systemic approach, prone to manage the complex and chaotic aspects characterizing living organisms. Ultimately, environmental pathology should be interested in improving the well-being of individuals and the population, and ideally the health of the entire ecosystem/biosphere and should not focus merely on single diseases, diseased organs/tissues, cells and/or molecules.
\end{abstract}

Keywords: fractal; entropy; life; living organisms; system biology; biological interfaces

\section{Introduction}

Querying a scientific, biomedical search engine such as PubMed ${ }^{\circledR \circledR}$ for the keywords (as text word in title, abstract, Medical Subject Headings terms and subheadings) from the present title may return different results, depending on how the search string is composed. A single word search returned, respectively, 9217 results for "chaos", 158,255 results for "complexity", 100,872 results for "thermodynamics", but only 44 results for "environmental pathology" (last accessed on 9 April 2021). Unfortunately, the combined search of all four keywords returned no result and the same held true for combining the latter with each single previous keyword. Omitting the term "environmental" from the cumulative search returned only one result [1]. These findings prove a general interest in biomedical sciences for chaos theory, complexity and thermodynamics, though such topics have not so far fascinated pathologists in general and environmental pathologists in particular. Certainly, this is not due to a lack of advantages in the comprehension of pathophysiology processes, but rather to a somewhat traditional and conservative approach of pathologists to their topics $[2,3]$. In fact, complexity science and chaos theory have gone far beyond scientific, academic interest, becoming a common scientific divulgation theme. Nevertheless, medical disciplines, and pathology in particular, still rely on a deterministic, reductionistic approach and still hesitate to fully appreciate the intrinsic complexity of living beings, aside from some noticeable exceptions [4-9].

Herein, complexity, chaos and thermodynamics are introduced with specific regard to living organisms and biomedical sciences; then, their interconnections and implications in environmental pathology are discussed, with particular regard to a morpho-pathological, image analysis-based approach. 


\section{Complexity, Chaos and Thermodynamics in Living Systems}

\subsection{Complexity}

To date there is no univocal, inclusive, exhaustive definition of complexity. Nevertheless, a complex system may be considered as a system whose behaviour is not simply derivable from the behaviour of its single parts (the whole is greater than the sum of its parts), due to the phenomenon of "emergence" as the collective, consequent behaviour of these parts interacting with each other. Accordingly, the amount of information needed to detail the behaviour of such system can be referred to a measure of its complexity [10-14]. Referring to the theory of communication, the more the entropy of a system increases, the more the related informative content decreases [15]. The latter concept will be further expanded in the paragraph about thermodynamics. The computational, informative, physical measure of complexity, among others, are not satisfactory in describing living systems, where no definitive definition/measure is available [10-14]. Nevertheless, fractal dimension, as a possible measure of morphological complexity, has been used in pathology $[8,16]$.

Apart from emergence, as a property of all complex systems, living systems also display "self-organizing" behaviour, referring to the capacity of controlling their own behaviour without the need of internal or external control, adaptive properties (complex adaptive system) and macroscopic complex changing behaviour (dynamic systems) [14]. It should be stressed that self-organization concept was primarily conceptualized by researchers in mathematics and physics, and should be referred to as possible intrinsic properties of physics and chemistry, rather than a complementary mechanism of evolution alongside natural selection, though some authors hope for a possible synthesis [17]. To some extent, this latent physicism was appreciable in the most famous work of D'Arcy Wentworth Thompson, On Growth and Form [18]. Another peculiarity of living organisms, as complex adaptive systems, is that they thrive at the edge of order and disorder $[14,19]$. In fact, starting from perfectly ordered and simple systems, a peak of complexity is reached where some underlying rule is assumed, which then decreases the more the disorder increases, assuming no underlying rule exists (stochastic systems) [10]. This borderline behaviour is extremized in chaotic systems. Moreover, such somewhat biphasic order to complexity diagram leads to the idea that disease has to be primarily regarded as a reduction/loss of inherent complexity, rather than a mere reduction/loss of order. As a consequence, fractal analysis has been proposed as a method to evaluate the complexity reduction associated to pathological changes in tissues $[8,16,20,21]$.

Starting from Charles Darwin, biologists are seeking for general, universal properties among living organisms and, in particular, molecular biology tried to explain such properties in terms of molecules, with particular emphasis to DNA, as the universal language of transmission of the biological information through generation and as a possible source of variation during evolution. This is according to the following logical approach: organisms are approached at the microscopic, molecular level, with particular regard to the interactions among molecules, to the function associated with such interactions and to the possible DNA-related variations. As a consequence, the macroscopic behaviour of an organisms is deduced from the possible ways the constituting molecules combine with each other. Though the molecular approach has proven useful for medical implications, unfortunately it is at the present ineffective to explain real-life complexity, being extremely reductionistic and potentially effective only in rare, if any, one-to-one molecule interactive systems [13]. To put it simply, the excessive attention paid to fine molecular details may lead someone to "not see the wood for the trees". More recently, in the post-genomic era, network analysis has been applied at different hierarchical levels in systems biology to study organisms as whole integrated systems, and to study how protein-protein interaction network ("interactome") is related to functions [22-24].

\subsection{Chaos}

The scientific method relies on the logical succession of the following main steps: phenomena observation, proposing explanations, testing explanations. Proposing expla- 
nations implies the translation of the observed phenomena into a model, in particular, a mathematical one $[5,25]$. When applicable natural phenomena are approximated to linear models, where proportionality exists between causes and effects, and where each component can be analyzed separately and its effects summed algebraically to obtain the cumulative effects (the whole is equal to the sum of its parts). If linear models are not suitable to explain phenomena, more complex nonlinear models may be required, where components cannot be analyzed separately and algebraically summed to obtain a systemic effect (the whole is greater than the sum of its parts) [26].

In spite of this, the fundamental reductionist assumption is based on the knowledge of the initial conditions, given which the future behavior of the system can be described in a deterministic manner. Nevertheless, even if we were able to track each particle in the universe at the subatomic level, according to the concept of universal determinism of Laplace [27], we would be unable to predict any physical phenomena, biologically included [5]. According to Heisenberg, there is a fundamental precision limit in the predictability of the values for definite pairs of complementary variables (position and momentum of a particle) starting from initial condition. In fact, Heisenberg's uncertainty principle "states a fundamental property of quantum systems and is not a statement about the observational success of current technology" [28]. Aside from quantum physics, generally speaking, the experimental act of observing reality implies an inevitable impact on the latter, unpredictably affecting the resulting measure (observer effect). The observer effect is instrument-related, which is notably different from the uncertainty principle $[29,30]$.

In system modeling, many differential equations may lead to approximate solutions. Moreover, both analytic and numerical methods rely on irrational number, implying the practical need of rounding to a significant figure. In systems characterized by sensitivity to initial conditions, as stressed for the first time by Poincaré, such approximation may result in drastic variation in the predicted behavior [5,31-33]. As observed and stressed by Lorenz in weather forecast modeling (a typical example of complex dynamic system modelling), the iterative processes of nonlinear systems exponentially amplify such small initial differences that, contrary to linear systems, where differences in the initial conditions proportionally affect the predicted behavior, disproportionate effects may result [5,34]. This means that chaotic systems are inheritably unpredictable, though it does not imply they are not cognoscible or behave randomly. The apparently contradictory term "deterministic chaos" has been introduced to denote chaotic behavior expressed by nonlinear systems, where the time evolution of their state can be uniquely determined from their initial conditions, according to proper dynamical laws [33].

Among others, chaotic systems can be characterized in terms of strange attractors, bounded regions of the phase space (a multidimensional space, whose axes correspond to each coordinate necessary to describe the state of a physical system) where the trajectories generated by equations converge, forming loops without intersecting one another. Interestingly, strange attractors have fractal dimensions [5,33]. According to Prigogine, rather than referring to trajectories and points in the phase space, one should refer to a region defined in terms of probability distribution [35]. The conceptual and substantial difference between deterministic chaos, as previously defined, and stochastic chaos, definable in terms of state transitions, rather than in terms of dynamics, should be stressed [36,37].

Living organism displays chaotic behavior at different levels of organization, and both physiology and pathophysiology, e.g., cardiovascular, nervous and respiratory systems, can be approached by methods of nonlinear (chaotic) dynamic systems [26,33,38-46]. Accordingly, pathological state can be ascribed to the alteration of the attractor's basin of attraction, and also in the transition from a (chaotic) strange attractor to (periodic) limit cycle or to a fixed point attractor [47-49]. The end of a biological function, and ultimately death, may be visualized as the rest point of a fixed-point attractor.

Network biology modeling has been proposed to identify the transition from normal to disease state in complex diseases, corresponding to the bifurcation point in dynamical systems theory. In particular, three states are recognized during progression: normal, pre- 
disease and disease state. Both normal and disease states are steady states characterized by high resilience and robustness. On the contrary, the pre-disease state shows low resilience and robustness. Drastic drop of state-transition-based local network entropy, as a dynamical network biomarker criterion, ensures the identification of pre-disease state, serving as a general early-warning indicator of imminent transitions, where traditional biomarkers fail [50].

\subsection{Thermodynamics}

Thermodynamics deals with the physical properties of systems of matter and energy. Though originally macroscopic, thermodynamics turned microscopic with the statistical mechanics approach of Boltzmann, where the emergent macroscopic properties of the system were inferred, in statistical terms, from the microscopic properties of the compounding particles. In particular, Boltzmann argued that the macrostate of a system was the average of the different possible molecular microstates, and applied this concept to entropy [11,14,51]. Accordingly, entropy, the most degraded form of energy not able to produce further work was associated with the disorder of the molecules characterizing that specific macrostate, this being the disordered status that was more probable than the ordered one at equilibrium [11,14,51]. Interestingly, Shannon approached information measures following the same idea of the macrostate (information about the source of message) as a function of possible microstates (possible messages sent by the source), consequently deriving a probabilistic definition of entropy (Shannon entropy), closely related to the definition of entropy given by Boltzmann, leading to the observation that the informative content of a system decreases, with the increasing entropy; thus, the disorder of the system [14,15]. Nevertheless, the first to link entropy to information was Leo Szilard, who solved the Maxwell's demon paradox, suggesting that the molecule sorting activity of such a hypothetic entity (demon) inevitably caused energy expenditure that ultimately contributed to increasing entropy, according to the second law of thermodynamics, which, at that time, Maxwell's demon paradox seemed to violate [14]. Interestingly, the negative correlations between decreasing Haralick's "Sum Entropy" (as a measure of the disorder of a vector form the gray level co-occurrence matrix) and increasing fractal dimension (obtained through grayscale differential box counting) was documented in the liver of common carp dosed with perfluorooctanoic acid (PFOA) [20].

Prigogine studied the systems far from (thermodynamic) equilibrium (non equilibrium) and coined the term "dissipative structures", referring to dynamic open systems displaying self-organization and orderliness; thus, low (internal) entropy. Living organisms, as dynamic complex systems far from equilibrium, behave as dissipative structures, maintaining their internal order (low-entropy) thanks to high-enthalpy, low-entropy intakes from the environment, and returning low-enthalpy, high entropy wastes (heat, excretes, egesta) to the latter [51]. As stressed by Schrödinger, they have to export the entropy they generate to the outer environment in order to live [52]. Interestingly, anatomical structures involved in this "entropy purge" (e.g., lung) show fractal organization [53,54]. Referring to the pathological context, morpho-functional alteration at the different integration scales of living organisms (from subcellular to organismic level) may affect the original complexity and the "entropy purge" needed to maintain the organism far from equilibrium, thus healthy and ultimately alive [20,55]. Death arises as the organism reaches the thermodynamic equilibrium and as its molecules reach the state of maximum (most probable) disorder.

\section{Pathology and Environmental Pathology}

\subsection{General Pathology}

In spite of the multitude of possible causes of diseases (so named noxae), tissue lesions and responses are limited in number and occur according to common pathways. General pathology deals with the latter and may be depicted as the common trunk of the ideal tree, conjoining the roots of basic sciences and biomedical disciplines (physics, 
chemistry, anatomy, microbiology, physiology, etc.) to the crown of medical clinical disciplines (internal medicine, surgery, etc.), being a multidisciplinary, translational biomedical discipline [56].

From a historical perspective, the masterpiece De sedibus et causis morborum per anatomen indagatis (On the Seats and Causes of Diseases as Investigated by Anatomy) by Giovanni Battista Morgagni represented a milestone in pathology, clearly identifying the pathological basis of diseases at organ level (anatomoclinical correlates) and posing the basis of the modern systemic (special) pathology [57-59]. Afterwards, such anatomoclinical correlates were extended down at the tissue level by Xavier Bichat and at cellular level by Rudolph Virchow, who introduced the cellular theory in pathology, identifying the main cell alterations/responses, so founding cellular pathology and the basis of modern medicine $[56,58,60]$. General pathology (Allgemeine Pathologie) was first introduced in medical courses in Germany in 19th century, searching for the elementary lesions as the basis of diseases. Rudolph Albert Peters introduced the concept of "biochemical lesion" as subcellular metabolic alteration, and Linus Pauling the concept of "molecular pathology", as an alteration of the configuration of key molecules, altering cell functionality. Summarizing, over the centuries, sick organisms were dissected from the macroscopic down to the molecular level in order to elucidate the pathophysiology associated with each disease, as the pathological alteration of the physiological normal pathways [56]. This frankly reductionistic "molecular dissection" certainly led to important improvement both in terms of diagnosis and therapy; nevertheless, it should be stressed that the object of medicine is primarily to heal individuals, possibly communities and not molecules, because, as taught by complexity science, the individual is greater than the sum of their composing molecules.

\subsection{Environmental Pathology}

Environmental pathology is a branch of general pathology, originally dealing with environmental (climatic, physical) factors acting as a cause of disease. To date, the major interest in environmental pathology is in the study of environmental pollutants as a cause of disease [61-63]. As previously stressed, general pathology is a multidisciplinary, translational biomedical discipline; this holds true to a greater extent, if possible, with environmental pathology, due to the close relationships with other related disciplines, such as environmental toxicology, ecotoxicology, and environmental chemistry. Moreover, because environmental pollutants do not act singly and are normally present in the environment at the limit of instrumental detection, a chronic low dose, or possibly a "multiresidual" approach, should be adopted to monitor other environmental and individual parameters (e.g., environmental physico-chemical parameters, age, body parameters, concurrent pathologies, etc.), leading to complex modeling that stresses the need of a complexity-oriented approach [20].

As for other multidisciplinary disciplines, environmental pathology may rely on different techniques, though a morpho-pathological approach represents a good compromise in terms of diagnostic robustness, reliability and affordability, representing, to date, the gold standard in diagnostic pathology. Moreover, in a schematic representation of biomarkers usable for assessing the effects of pollutant stress with increasing ecological relevance and time of response, from the molecular level (timely responsive, but prompt recovering when stressor ceases), up to ecosystem level (slowly responsive and possibly not recovering when stressor ceases), the use of morphological biomarkers from cellular to tissue/organ level may represent a good compromise in terms of response and recovery time, and potential ecological significance $[64,65]$.

\section{Image Analysis in Environmental Pathology}

Approaching morpho-pathological alterations by means of image analysis can improve discriminative power. The image analysis approach to liver histopathology in common carp exposed to PFOA resulted in a better discrimination among experimental 
classes compared to high performance liquid chromatography with electro-spray ionization tandem mass spectrometry [66]. Interestingly, though PFOA liver concentrations at environmentally relevant exposure were under the level of detection (LOD), increased expression levels of glutathione S-transferase (GST) gene were documented [67]. Aside from providing information about possible PFOA pathophysiology, the concordance between image analysis and biomolecular data stresses the usefulness of a morpho-pathological, image analysis-based approach in environmental pathology [68].

Referring to other image analysis techniques, advancements in radiological image processing techniques have led to "radiomics" that are able to extract qualitative and quantitative data from clinical images. Thanks to a computational approach, radiomics data may be correlated and integrated with genomic data, resulting in "radiogenomics" as an emerging precision medicine approach [69]. Recently, the opportunity to merge precision medicine data, dealing with singular person health with public health data and to aggregate, integrate and analyze them collectively by means of Big Data tools, has been proposed. Accordingly, the integration of omics, clinical, social, environmental and demographic results in "precision public health bridges the gap between individualized and collective medicine, and gives equal opportunities both to clinicians and public health policy makers [70].

\section{Perspectives}

As previously reported, the evaluation of complexity changes has been assessed, adopting fractal analysis to experimentally document the effect of toxics in aquatic organisms, also at ecologically relevant concentrations [20,21,71]. Moreover, the relationship between complexity changes, in terms of fractal dimension, and informatics entropy has been reported [20]. Intriguingly, the experimental exposure of common carp to PFOA at ecologically relevant concentrations resulted in a counterintuitive increase in complexity, assessed by means of a grayscale differential box counting method, at liver cell level. Such a complexity increase was associated with incipient, mild, reversible cell alteration (cloudy swelling). As a consequence, this histopathological state was regarded as an initial adaptive strategy, a possible hormetic response to cope with toxicant challenge, rather than a mere degenerative, disadaptive status [20,72]. An analogous complexity system increase associated with detoxication and antioxidant protective processes secondary to mild cell stress was observed by Moore as a biphasic or hormetic response in a cell model, adopting network and graph theory. Increasing stress severity and cell injury resulted in cell functional impairment and dysfunction [73]. This resultant correspondence between structural (fractal analysis) and functional (network theory) methods put into perspective the potentialities, either in diagnosis or in research, of the morphological approach to complexity. Traditionally, pathology relies on morphological (histopathological) tissue assessment, though it is rather conservative and reticent to rely on the study of complexity, with the noticeable exception of, among others, Gabriel Landini, who specifically addressed this latter topic in microscopy and image analysis $[9,74,75]$. Fortunately and currently, digital image analysis is already used in pathology and it will be more widely used in the future [76-78]. As a consequence, it would be only a matter of awareness of potentialities related to the study of complexity changes in tissue sections.

Living systems show hierarchic organization levels; therefore, structural and/or functional transition zones are identifiable. Of particular interest are the former; they display clear interface properties and are approachable by means of morpho-pathological, image analysis-based methods. Bilayer membranes are the most pertinent example of such morpho-functional interfaces contributing to subcellular and cellular compartmentalization [79]. Examples of interfaces at the tissue/organ level include lungs, gills, kidney and intestine. Very interestingly, these interfaces display fractal properties and are implied in entropy purge from organisms $[53,54]$, their integrity and functionality being critical for maintaining organisms far from thermodynamic equilibrium [35,52]. 
From a morphological point of view, biological interfaces are traditionally assessed by means of a qualitative, descriptive histopathological approach. The adoption of morphometric techniques allows approaching them quantitatively (with evident improvement in the statistical evaluation of results) and testing them for possible complexity changes, prone to alter the thermodynamic asset of organism [20,68]. Referring to fish as key indicator organisms for laboratory and field ecotoxicological studies, gills can be referred to as the most extensive interface with aquatic environment and, accordingly, suitable biomarkers for aquatic pollution [80,81]. Though gill assessment is currently used in environmental and ecotoxicological studies, to date there is a lack of standardized methods to objectively quantify gill alterations and, as a consequence, lesions are assessed only qualitatively or semi-quantitatively [82,83]. Nevertheless, metrics, indices, and scores have been proposed to evaluate fish gill status $[84,85]$ and, more recently, the application of the Local Connected Fractal Dimension (LCFD) analysis was proposed as an objective, sensitive and specific method to study gill pathology [21] (Figure 1).
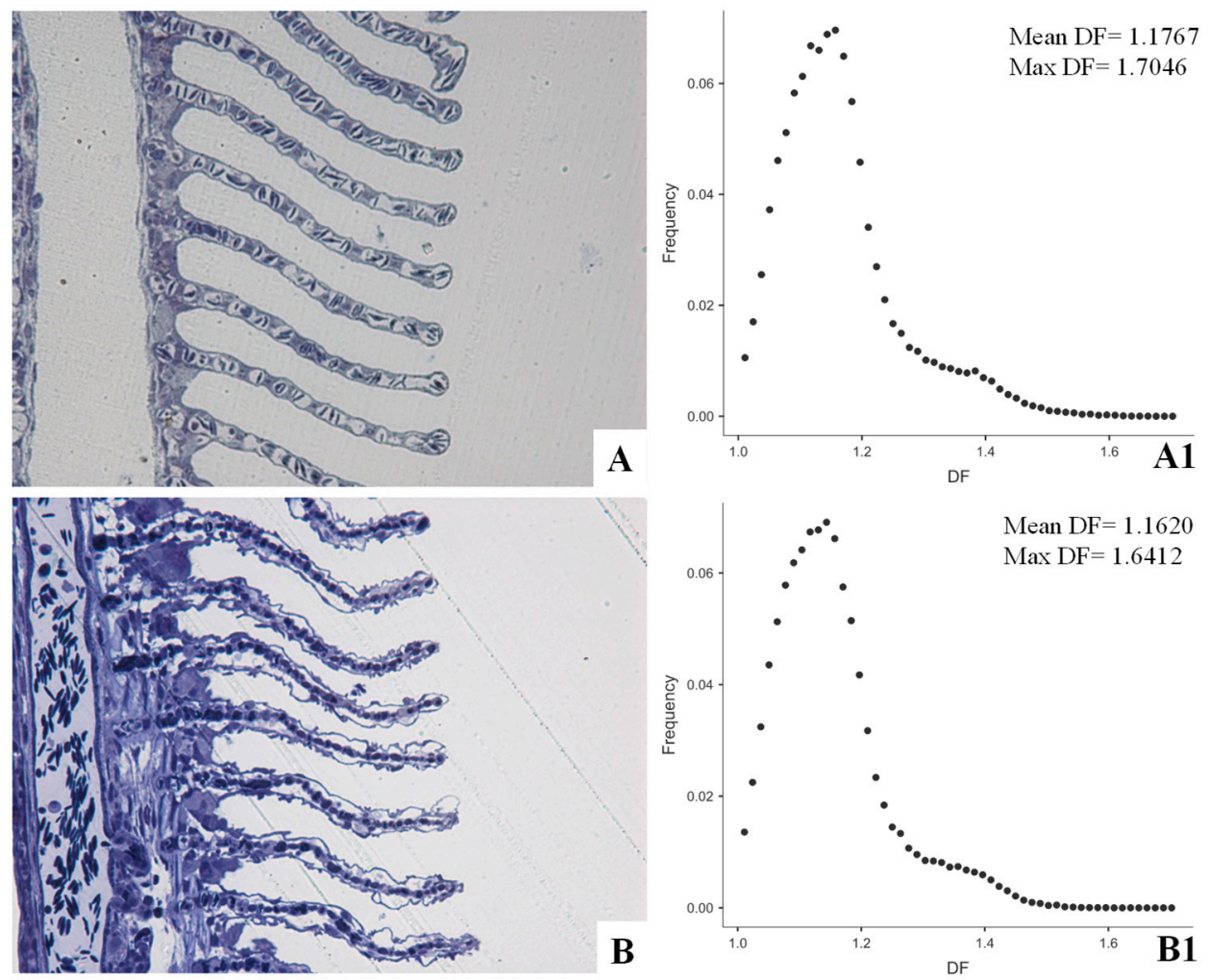

Figure 1. European sea bass, Dicentrarchus labrax (Linnaeus, 1758). Epon-Araldite embedded semithin sections stained with Toluidine Blue and observed at light microscopy. Secondary gill lamellae from normal (A) and Cd exposed (B) exemplars. Cadmium exposure affects both water-epithelial cell interface, where lifting, shrinkage and curling of epithelial cells are appreciable, and pillar cell-blood interface, where pillar cells (gill modified endothelial cells) coarctation results. Morphological evident alterations affect tissue complexity as measured by fractal dimension in binarized, outlined figures. Testing previous tissues for Local Connected Fractal Dimension (LCFD) results in the two scatter plots of frequency (ordinates) to fractal dimension (DF) (abscissa) (A1,B1). Accordingly, Cd exposure affects mean and maximal fractal dimension. Moreover, a slight left shift of the scatter plot is appreciable compared to normal tissue, resulting in a significant difference (Wilcoxon $\mathrm{W}, p<0.05$ ) in the paired frequencies. Further information, details about the application of LCFD analysis to gill pathology and about the histopathological, and ultrastructural effects of Cd exposure on European sea bass gills are available in Manera et al. [2,21,81].

Accounting for local variation in complexity, LCFD is better suited to screen gill than mean global fractal dimension, where opposite local variations may compensate each other on average, masking possible significant differences $[21,75,81]$. Being an operator-neutral 
method, it can be implemented and associated with discriminant analysis techniques as possible automated procedures to detect pathological tissue patterns with adequate confidence [21].

In perspective, more attention should be paid to biological interfaces, as complex structures where entropy is transferred among increasing organization levels and purged to the external environment, before they should finally disperse. Where and when this does not happen, a local (intra-organismic) increase in entropy occurs, which leads to complexity reduction, impaired information retention and transmission. Exogenous and/or endogenous toxin retention, and altered energy content use and transfer, will result in an impaired transfer of energy, matter and information, altering all the interfaces down to subcellular molecular level if organism countermeasures (in term of complexity increase) are not adequate to compensate for increased entropy load. This ultimately leads to a frank and chronic pathological state or even death if thermodynamic equilibrium is approached, representing a clear, innovative way to deal with pathology in general and environmental pathology in particular, which is more prone to approaching organisms in a systemic and dynamic view.

\section{Conclusions}

Biomedical disciplines traditionally approach living organisms by means of reductionistic and deterministic methods. In particular, organisms are dissected down to the molecular level in order to gain information about possible molecule to molecule interactions, to derive their macroscopic behavior. Given the complex and chaotic behaviors of living systems, this approach is extremely limited in terms of obtainable information and may lead to misinterpretation.

Approaching environment-organism biological interfaces by means of image analysis tools may result in an effective, objective and operator-neutral way to interpret complexity changes and possible informative content changes at the tissue/organ level and related consequences for the entire organism as an integrated part of the higher hierarchical systems. This approach relies on image analysis methods already in use in digital pathology, though also requires a novel mental paradigm and awareness of the dynamic essence of organisms within ecosystems.

Environmental pathology, as a multidisciplinary discipline, should grant privilege to an integrated, possibly systemic approach that is prone to manage the complex and chaotic aspects which characterize living organisms. Ultimately, environmental pathology should be interested in improving the well-being of individuals, and the population, and ideally the health of the entire ecosystem/biosphere and should not focus merely on single diseases and diseased organs/tissues, cells and/or molecules.

Funding: This review was partially funded by the University of Teramo, grant number FARDIBBIRI 00162.

Institutional Review Board Statement: Ethical review and approval were waived for this study, because being in form of perspective article it relies on the analysis and discussion of previous references.

Informed Consent Statement: Not applicable.

Data Availability Statement: No new data were created or analyzed in this study. Data sharing is not applicable to this article.

Conflicts of Interest: The authors declare no conflict of interest. The funders had no role in the writing of the manuscript.

\section{References}

1. Martin-Araguz, A.; Ruiz-Alâez, A.; De La Garcia Rocha, M.L.; Fernândez-Armayor, V.; Delgado-Reyes, S.; Moreno-Martincz, J.M. Caos determinista, cinemâtica de fluidos y geometria fractal en el sistema carotideo. Rev. Neurol. 1997, $25,2021-2031$.

2. Manera, M.; Sayyaf Dezfuli, B.; DePasquale, J.A.; Giari, L. Multivariate approach to gill pathology in European sea bass after experimental exposure to cadmium and terbuthylazine. Ecotoxicol. Environ. Saf. 2016, 129, 282-290. [CrossRef] 
3. Al-Janabi, S.; Huisman, A.; Van Diest, P.J. Digital pathology: Current status and future perspectives. Histopathology 2012, 61, 1-9. [CrossRef]

4. Goodwin, J.S. A piece of my mind. Chaos, and the limits of modern medicine. JAMA 1997, 278, 1399-1400. [CrossRef] [PubMed]

5. Oestreicher, C. A history of chaos theory. Dialogues Clin. Neurosci. 2007, 9, 279-289.

6. Hueso, M.; Cruzado, J.M.; Torras, J.; Navarro, E. ALUminating the path of atherosclerosis progression: Chaos theory suggests a role for alu repeats in the development of atherosclerotic vascular disease. Int. J. Mol. Sci. 2018, 19, 1734. [CrossRef] [PubMed]

7. Sigston, E.A.W.; Williams, B.R.G. An Emergence Framework of Carcinogenesis. Front. Oncol. 2017, 7, 198. [CrossRef]

8. Varela, M.; Ruiz-Esteban, R.; Mestre De Juan, M.J. Chaos, Fractals, and Our Concept of Disease. Perspect. Biol. Med. 2010, 53, 584-595. [CrossRef]

9. Eid, R.A.; Landini, G. Quantification of the Global and Local Complexity of the Epithelial-Connective Tissue Interface of Normal, Dysplastic, and Neoplastic Oral Mucosae Using Digital Imaging. Pathol. Res. Pract. 2003, 199, 475-482. [CrossRef] [PubMed]

10. Edmonds, B. What is Complexity?-The philosophy of complexity per se with application to some examples in evolution. In The Evolution of Complexity: The Violet Book of "Einstein Meets Magritte"; Heylighen, F., Bollen, J., Riegler, A., Eds.; Kluwer Academic Publishers: Dordrecht, The Netherlands, 1999; pp. 1-13.

11. Bar-Yam, Y. Dynamics of Complex Systems; Addison-Wesley: Reading, MA, USA, 1997; ISBN 0201557487.

12. Adami, C. What is complexity? BioEssays 2002, 24, 1085-1094. [CrossRef]

13. Kaneko, K. Life: An Introduction to Complex Systems Biology; Springer: Berlin/Heidelberg, Germany; New York, NY, USA, 2006; ISBN 9783540326663.

14. Mitchell, M. Complexity A Guided Tour; Oxford University Press: Oxford, MS, USA, 2009; ISBN 9780195124415.

15. Shannon, C.E. A Mathematical Theory of Communication. Bell Syst. Tech. J. 1948, 27, 379-423. [CrossRef]

16. Cross, S.S.; Cotton, D.W.K. Chaos and antichaos in pathology. Hum. Pathol. 1994, 25, 630-637. [CrossRef]

17. Johnson, B.R.; Lam, S.K. Self-organization, natural selection, and evolution: Cellular hardware and genetic software. Bioscience 2010, 60, 879-885. [CrossRef]

18. Thompson, D.W. On Growth and Form; The MacMillan Company: New York, NY, USA, 1945; ISBN 9780521437769.

19. Chan, S. Complex Adaptive Systems. ESD.83 Res. Semin. Eng. Syst. 2001, 31, 1-9.

20. Manera, M.; Dezfuli, B.S.; Castaldelli, G.; DePasquale, J.A.; Fano, E.A.; Martino, C.; Giari, L. Perfluorooctanoic Acid Exposure Assessment on Common Carp Liver through Image and Ultrastructural Investigation. Int. J. Environ. Res. Public Health 2019, 16, 4923. [CrossRef] [PubMed]

21. Manera, M.; Giari, L.; De Pasquale, J.A.; Sayyaf Dezfuli, B. Local connected fractal dimension analysis in gill of fish experimentally exposed to toxicants. Aquat. Toxicol. 2016, 175, 12-19. [CrossRef] [PubMed]

22. Thomas, S.; Bonchev, D. A survey of current software for network analysis in molecular biology. Hum. Genom. 2010, 4, 353-360. [CrossRef] [PubMed]

23. Barabási, A.L.; Oltvai, Z.N. Network biology: Understanding the cell's functional organization. Nat. Rev. Genet. 2004, 5, 101-113. [CrossRef]

24. Li, S.; Armstrong, C.M.; Bertin, N.; Ge, H.; Milstein, S.; Boxem, M.; Vidalain, P.O.; Han, J.D.J.; Chesneau, A.; Hao, T.; et al. A Map of the Interactome Network of the Metazoan C. elegans. Science 2004, 303, 540-543. [CrossRef]

25. Carey, S.S. A beginner's Guide to Scientific Method, 4th ed.; Wadsworth, Cengage Learning: Boston, MA, USA, 2011.

26. Goldberger, A.L. Non-linear dynamics for clinicians: Chaos theory, fractals, and complexity at the bedside. Lancet 1996, 347, 1312-1314. [CrossRef]

27. Marquis de Laplace, P.S. Essai Philosophique sur les Probabilités, 5th ed.; Bachelier: Paris, France, 1825.

28. Busch, P.; Heinonen, T.; Lahti, P. Heisenberg's uncertainty principle. Phys. Rep. 2007, 452, 155-176. [CrossRef]

29. Baclawski, K. The Observer Effect. In Proceedings of the 2018 IEEE International Conference on Cognitive and Computational Aspects of Situation Management, CogSIMA 2018, Boston, MA, USA, 11-14 June 2018; Institute of Electrical and Electronics Engineers Inc.: Piscataway, NJ, USA, 2018; pp. 83-89.

30. Sassoli de Bianchi, M. The Observer Effect. Found. Sci. 2013, 18, 213-243. [CrossRef]

31. Iglesias, A.; Gutiérrez, J.M.; Güémez, J.; Matías, M.A. Chaos suppression through changes in the system variables and numerical rounding errors. Chaos Solitons Fractals 1996, 7, 1305-1316. [CrossRef]

32. Poincaré, H. Sur les solutions périodiques et le principe de moindre action. CR Acad. Sci. Paris 1896, 123, 915-918.

33. Schuster, H.G.; Just, W. Deterministic Chaos, 4th ed.; Wiley-VCH Verlag GmbH \& Co. KGaA: Weinheim, Germany, 2005.

34. Lorenz, E.N. Deterministic Nonperiodic Flow. J. Atmos. Sci. 1963, 20, 130-141. [CrossRef]

35. Prigogine, I.; Stengers, I. The End of Certainty; The Free Press: New York, NY, USA, 1997; ISBN 0684837056.

36. Yao, Q.; Tong, H. On prediction and chaos in stochastic systems. Philos. Trans. R. Soc. London. Ser. A Phys. Eng. Sci. 1994, 348, 357-369. [CrossRef]

37. Timmer, J.; Häussler, S.; Lauk, M.; Lücking, C.H. Pathological tremors: Deterministic chaos or nonlinear stochastic oscillators? Chaos 2000, 10, 278-288. [CrossRef]

38. Garfinkel, A.; Spano, M.L.; Ditto, W.L.; Weiss, J.N. Controlling cardiac chaos. Science 1992, 257, 1230-1235. [CrossRef] [PubMed]

39. Chialvo, D.R.; Gilmour, R.F.; Jalife, J. Low dimensional chaos in cardiac tissue. Nature 1990, 343, 653-657. [CrossRef]

40. Denton, T.A.; Diamond, G.A.; Helfant, R.H.; Khan, S.; Karagueuzian, H. Fascinating rhythm: A primer on chaos theory and its application to cardiology. Am. Heart J. 1990, 120, 1419-1440. [CrossRef] 
41. King, C.C. Fractal and chaotic dynamics in nervous systems. Prog. Neurobiol. 1991, 36, 279-308. [CrossRef]

42. Babloyantz, A.; Destexhe, A. Low-dimensional chaos in an instance of epilepsy. Proc. Natl. Acad. Sci. USA 1986, 83, $3513-3517$. [CrossRef] [PubMed]

43. Rabinovich, M.I.; Abarbanel, H.D.I. The role of chaos in neural systems. Neuroscience 1998, 87, 5-14. [CrossRef]

44. Sarbadhikari, S.N.; Chakrabarty, K. Chaos in the brain: A short review alluding to epilepsy, depression, exercise and lateralization. Med. Eng. Phys. 2001, 23, 447-457. [CrossRef]

45. Mangin, L.; Fiamma, M.N.; Straus, C.; Derenne, J.P.; Zelter, M.; Clerici, C.; Similowski, T. Source of human ventilatory chaos: Lessons from switching controlled mechanical ventilation to inspiratory pressure support in critically ill patients. Respir. Physiol. Neurobiol. 2008, 161, 189-196. [CrossRef] [PubMed]

46. Vena, A.; Conte, E.; Perchiazzi, G.; Federici, A.; Giuliani, R.; Zbilut, J.P. Detection of physiological singularities in respiratory dynamics analyzed by recurrence quantification analysis of tracheal sounds. Chaos Solitons Fractals 2004, 22, 869-881. [CrossRef]

47. Mackey, M.C.; Glass, L. Oscillation and chaos in physiological control systems. Science 1977, 197, 287-289. [CrossRef]

48. Otero-Siliceo, E.; Arriada-Mendicoa, N. Is it healthy to be chaotic? Med. Hypotheses 2003, 60, 233-236. [CrossRef]

49. Poon, C.S.; Merrill, C.K. Decrease of cardiac chaos in congestive heart failure. Nature 1997, 389, 492-495. [CrossRef] [PubMed]

50. Liu, R.; Li, M.; Liu, Z.P.; Wu, J.; Chen, L.; Aihara, K. Identifying critical transitions and their leading biomolecular networks in complex diseases. Sci. Rep. 2012, 2, 1-9. [CrossRef]

51. Haynie, D.T. Biological Thermodynamics, 2nd ed.; Cambridge University Press: Cambridge, UK, 2008 ; ISBN 9789896540821.

52. Schrödinger, E. What Is Life? The Physical Aspect of the Living Cell; Cambridge University Press: Cambridge, UK, 1944.

53. Gheorghiu, S.; Kjelstrup, S.; Pfeifer, P.; Coppens, M.O. Is the Lung an Optimal Gas Exchanger? In Fractals in Biology and Medicine; Losa, G.A., Merlini, D., Nonnenmacher, T.F., Weibel, E.R., Eds.; Birkhäuser Verlag: Basel, Switzerland, 2005; pp. 31-42. ISBN 978-3-7643-7172-2.

54. Oliveira, C.L.N.; Araújo, A.D.; Bates, J.H.T.; Andrade, J.S.; Suki, B. Entropy Production and the Pressure-Volume Curve of the Lung. Front. Physiol. 2016, 7, 73. [CrossRef]

55. Kurakin, A. The self-organizing fractal theory as a universal discovery method: The phenomenon of life. Theor. Biol. Med. Model. 2011, 8, 1-66. [CrossRef]

56. Majno, G.; Joris, I. Cells, Tissues, and Disease: Principles of General Pathology; Oxford University Press: New York, NY, USA, 2004; ISBN 0199748926.

57. Zampieri, F.; Zanatta, A.; Thiene, G. An etymological “autopsy" of Morgagni's title: De sedibus et causis morborum per anatomen indagatis (1761). Hum. Pathol. 2014, 45, 12-16. [CrossRef] [PubMed]

58. Magner, L.N. A History of Medicine, 2nd ed.; Taylor \& Francis: Boca Raton, FL, USA, 2005; ISBN 3527404139.

59. Morgagni, J.B. De Sedibus, et Causis Morborum per Anatomen Indagatis; Remondini: Venezia, Italy, 1761.

60. Virchow, R. Die Cellularpathologie; Verlag von August Hirschwald: Berlin, Germany, 1859.

61. Epstein, S.S. Environmental pathology. A review. Am. J. Pathol. 1972, 66, 352-374. [PubMed]

62. Popper, H.; Selikoff, I.J. What is environmental pathology? Am. J. Med. 1981, 70, 218-220. [CrossRef]

63. Centeno, J.A.; Mullick, F.G.; Ishak, K.G.; Franks, T.J.; Burke, A.P.; Koss, M.N.; Perl, D.P.; Tchounwou, P.B.; Pestaner, J.P. Environmental Pathology. In Essentials of Medical Geology; Revised ed.; Selinus, O., Ed.; Springer: Dordrecht, The Netherlands, 2013; pp. 569-596. ISBN 9789400743755.

64. Adams, S.M.; Shepard, K.L.; Greeley, M.S.; Jimenez, B.D.; Ryon, M.G.; Shugart, L.R.; McCarthy, J.F.; Hinton, D.E. The use of bioindicators for assessing the effects of pollutant stress on fish. Mar. Environ. Res. 1989, 28, 459-464. [CrossRef]

65. Manera, M. I Biomarcatori nel Monitoraggio Ambientale_Pesci Ossei ed Ecosistemi Acquatici; Aracne: Rome, Italy, 2013; ISBN 978-88-548-6221-0.

66. Manera, M.; Giari, L.; Vincenzi, F.; Guerranti, C.; Depasquale, J.A.; Castaldelli, G. Texture analysis in liver of common carp (Cyprinus carpio) sub-chronically exposed to perfluorooctanoic acid. Ecol. Indic. 2017, 81, 54-64. [CrossRef]

67. Rotondo, J.C.; Giari, L.; Guerranti, C.; Tognon, M.; Castaldelli, G.; Fano, E.A.; Martini, F. Environmental doses of perfluorooctanoic acid change the expression of genes in target tissues of common carp. Environ. Toxicol. Chem. 2018, 37, 942-948. [CrossRef]

68. Manera, M.; Castaldelli, G.; Fano, E.A.; Giari, L. Perfluorooctanoic acid-induced cellular and subcellular alterations in fish hepatocytes. Environ. Toxicol. Pharmacol. 2021, 81, 103548. [CrossRef]

69. Shui, L.; Ren, H.; Yang, X.; Li, J.; Chen, Z.; Yi, C.; Zhu, H.; Shui, P. The Era of Radiogenomics in Precision Medicine: An Emerging Approach to Support Diagnosis, Treatment Decisions, and Prognostication in Oncology. Front. Oncol. 2021, 10, 3195. [CrossRef] [PubMed]

70. Velmovitsky, P.E.; Bevilacqua, T.; Alencar, P.; Cowan, D.; Morita, P.P. Convergence of Precision Medicine and Public Health Into Precision Public Health: Toward a Big Data Perspective. Front. Public Health 2021, 9, 561873. [CrossRef]

71. Manera, M.; Sayyaf Dezfuli, B.; Depasquale, J.A.; Giari, L. Pigmented macrophages and related aggregates in the spleen of european sea bass dosed with heavy metals: Ultrastructure and explorative morphometric analysis. Microsc. Res. Tech. 2018, 81, 351-364. [CrossRef] [PubMed] 
72. Manera, M.; Sayyaf Dezfuli, B.; Castaldelli, G.; Martino, C.; Giari, L. Grayscale differential box counting as a measure of complexity of liver texture in common carp (Cyprinus carpio) sub-chronically exposed to perfluorooctanoic acid (PFOA). In Proceedings of the Abstracts of the 55th Congress of the European Societies of Toxicology (EUROTOX 2019) TOXICOLOGY SCIENCE PROVIDING SOLUTIONS, Helsinki, Finland, 8-11 September 2019; Toxicology Letters; 2019, Volume 314, p. S186. [CrossRef].

73. Moore, M.N. Is toxicological pathology characterised by a loss of system complexity? Mar. Environ. Res. 2010, 69, S37-S41. [CrossRef]

74. Landini, G. Fractals in microscopy. J. Microsc. 2011, 241, 1-8. [CrossRef]

75. Landini, G.; Murray, P.I.; Misson, G.P. Local connected fractal dimensions and lacunarity analyses of 60 degrees fluorescein angiograms. Investig. Ophthalmol. Vis. Sci. 1995, 36, 2749-2755.

76. Laurinavicius, A.; Laurinaviciene, A.; Dasevicius, D.; Elie, N.; Plancoulaine, B.; Bor, C.; Herlin, P. Digital image analysis in pathology: Benefits and obligation. Anal. Cell. Pathol. 2012, 35, 75-78. [CrossRef]

77. Pantanowitz, L. Digital images and the future of digital pathology. J. Pathol. Inform. 2010, 1, 15. [CrossRef] [PubMed]

78. Kayser, G.; Kayser, K. Quantitative pathology in virtual microscopy: History, applications, perspectives. Acta Histochem. 2013, 115, 527-532. [CrossRef]

79. Karp, G. Cell and Molecular Biology; John Wiley \& Sons, Inc.: Hoboken, NJ, USA, 2010.

80. Bernet, D.; Schmidt, H.; Meier, W.; Burkhardt-Holm, P.; Wahli, T. Histopathology in fish: Proposal for a protocol to assess aquatic pollution. J. Fish Dis. 1999, 22, 25-34. [CrossRef]

81. Manera, M.; Giari, L.; DePasquale, J.A.; Dezfuli, B.S.S. European sea bass gill pathology after exposure to cadmium and terbuthylazine: Expert versus fractal analysis. J. Microsc. 2016, 261, 291-299. [CrossRef] [PubMed]

82. Mallatt, J. Fish gill structural changes induced by toxicants and other irritants: A statistical review. Can. J. Fish. Aquat. Sci. 1985, 42, 630-648. [CrossRef]

83. Gomes, I.D.; Nascimento, A.A.; Sales, A.; Araújo, F.G. Can fish gill anomalies be used to assess water quality in freshwater Neotropical systems? Environ. Monit. Assess. 2012, 184, 5523-5531. [CrossRef] [PubMed]

84. Hawkins, A.D.; Thornton, C.; Kennedy, A.J.; Bu, K.; Cizdziel, J.; Jones, B.W.; Steevens, J.A.; Willett, K.L. Gill histopathologies following exposure to nanosilver or silver nitrate. J. Toxicol. Environ. Health Part A Curr. Issues 2015, 78, 301-315. [CrossRef] [PubMed]

85. Alvarado, N.E.; Quesada, I.; Hylland, K.; Marigómez, I.; Soto, M. Quantitative changes in metallothionein expression in target cell-types in the gills of turbot (Scophthalmus maximus) exposed to $\mathrm{Cd}, \mathrm{Cu}, \mathrm{Zn}$ and after a depuration treatment. Aquat. Toxicol. 2006, 77, 64-77. [CrossRef] 